\title{
Toxicity of cyanobacteria. Organotropy of cyanotoxins and toxicodynamics of cyanotoxins by species
}

\author{
Victoria Ilieva ${ }^{1}$, Magdalena Kondeva-Burdina ${ }^{1}$, Tzveta Georgieva ${ }^{2}$, Vera Pavlova ${ }^{3}$ \\ 1 Laboratory "Drug metabolism and drug toxicity", Department "Pharmacology, Pharmacotherapy and Toxicology", Faculty of Pharmacy, Medical \\ University - Sofia, Bulgaria \\ 2 Laboratory "GMO", National Center of Public Health and Analyses, Sofia, Bulgaria \\ 3 Laboratory"Chemical Factors" National Center of Public Health and Analyses, Sofia, Bulgaria \\ Corresponding author: Victoria Ilieva (viki.ilieva1991@gmail.com)
}

Received 10 June 2019 • Accepted 9 August 2019 • Published 10 October 2019

Citation: Ilieva V, Kondeva-Burdina M, Georgieva T, Pavlova V (2019) Toxicity of cyanobacteria. Organotropy of cyanotoxins and toxicodynamics of cyanotoxins by species. Pharmacia 66(3): 91-97. https://doi.org/10.3897/pharmacia.66.e37035

\begin{abstract}
As a result of blooming, some cyanobacteria (Microcystis, Anabaena, Planktothrix, etc.) produce toxins at concentrations that are high enough to poison and even kill animals and humans. According to Annex II of the Framework Directive 2000/60/EC, transformed into the Bulgarian legislation, for the characterization of surface water, at this stage, there are no acceptable limit values for cyanotoxins. Cyanotoxins include some of the strongest natural poisons, including those that could cause rapid death due to respiratory failure.
\end{abstract}

The aim of this publication is an overview of toxic cyanobacteria and toxicity mechanisms.

\section{Keywords}

cyanobacteria, mechanism of action, toxicity

\section{Cyanotoxins - general information}

Cyanotoxins are toxins produced by bacteria called cyanobacteria, also known as blue-green algae. Cyanobacteria are widely distributed, mostly found in lakes and oceans. There are conditions for their exponential propagation, which leads to flowering. Flowering cyanobacteria can produce cyanotoxins in concentrations that are high enough to poison and even kill animals and humans. Also, cyanotoxins can accumulate in other animal species such as fish, shellfish and crustaceans, and thus lead to poisoning as a result of their consumption. Cyanotoxins include some of the strongest natural poisons, including those that could cause rapid death due to respiratory failure
(Stewart et al. 2008). Examples of such toxins are strong neurotoxins, hepatotoxins, cytotoxins, and endotoxins. Exposure to these toxins may cause gastrointestinal tract disorders, skin rashes and symptoms similar to those of hay fever (Stewart et al. 2006). The cyanobacterial neurotoxin, designated BMAA ( $\beta$-Methylamino-L-alanine), can be considered as an environmental factor causing neurodegenerative diseases such as amyotrophic lateral sclerosis, Parkinson's and Alzheimer's disease (Holtcamp 2012). There is interest in the use of cyanotoxins and for military purposes (Dixit et al. 2005). In 1878 it was reported for the first time that the contact of living organisms with blue- 
green algae or cyanobacteria could have a fatal outcome. George Francis describes the flowering of watercourses in the Murray River Estuary in Australia as "a thick foam like green oil paint with a thickness of two to six inches." The wild animals that drink from this water died quickly and painfully (Francis et al. 1878). Most of the reported cases of poisoning with similar tusks are recorded in freshwater basins (Edwards 2011; Miller et al. 2010).

\section{Introduction}

Over the past few years emerging climate-related risks have been discussed.

For example, from the European Commission publication 2016 (FUTURE BRIEF: Identifying Emerging Risks for Environmental Policies March 2016 Issue 13) related to identifying new risks to environmental policies, it is clear that satellite imagery is now being used to identify and monitoring of phytoplankton in coastal areas of the Atlantic, with a view to providing early warning of algal blooms which may be toxic and pose a risk to life at sea and human health (Lindsey and Scott 2010). The US Environmental Protection Agency (US EPA) is developing a satellite-based early warning system to detect algal blooms. An EU ASIMUTH project (http://www.asimuth. $\mathrm{eu} /$ ) has developed a similar alert system for flowering along the Atlantic Ocean.

At the same time, the research network CYANOCOST (Cyanobacterial blooms and toxins in water resources: Occurrence, impacts, and management) was released in February 2018 with an open letter to the European Commission amending Council Directive 98/83 / EC on the quality of water intended for use in, human consumption. Microcystin-LR (MC-LR) is included in the proposal as a "chemical parameter," with a value of $1 \mu \mathrm{g} / \mathrm{L}$, along with other organic compounds added to the list (bisphenol A, haloacetic acids, nonylphenol, perfluorooctane sulfonate (PFOS). The inclusion of MC-LR in the proposed directive is the result of the established increase in microcirculation in European waters, which may pose health and environmental risks associated with toxic cyanobacteria.

Methods for monitoring water pollution include analytical chemical techniques such as chromatography and mass spectrometry; toxicological tests, as well as DNA-based methods designed to understand the effects of pollutants at the molecular level (Bae and Park 2014, Gavrilescu et al. 2015, Geissen et al. 2015, Hellou 2010, Pintado-Herrera et al. 2001).

The presence of cyanobacteria in Bulgarian water basins has been reported since the end of the $19^{\text {th }}$ century. In the second half of the $20^{\text {th }}$ century, the presence of harmful algae blooms was reported for the first time. In 2004, the first study, as published, It presented the results of analyses of samples of 15 water basins in the country (drinking water reservoirs: Iskar (Sofia), Yasna Polyana (Bourgas), Studena (Pernik), Bistritsa and Botunetz (Sofia), Katina, and lakes for fishing and water sports - from the Black Sea region - Shabla, Ezerets, Durankulak, Vaya and Mandra, from Sofia - Dolni Borgov and Druzhba and from Pernik - Choklyovoto Blato) (Pavlova et al. 2006).

\section{Discussion}

Classification of cyanotoxins according to the mechanism of action. Organotropism.

Cyanobacteria produce as a result of their life activity products that are toxic to other organisms, including humans.

Cyanobacterial toxins are classified by their mechanism of action on the body. Hepatotoxins (which affect the liver) are produced by certain strains of Cyanobacteria Microcystis, Anabaena, Oscillatoria, Nodularia, Nostoc, Cylindrospermopsin and Umezakia. Cyanobacteria of Cylindroapermopsis raciborski species can also release poisonous alkaloids, causing gastrointestinal symptoms or kidney disease in humans. Not all cyanobacteria of

Table 1. Classification according to chemical structure and target in the body (Chorus and Bartram 1999):

\begin{tabular}{|c|c|c|c|}
\hline $\begin{array}{l}\text { Chemical } \\
\text { structure }\end{array}$ & Cyanotoxins & $\begin{array}{c}\text { Target } \\
\text { structure } \\
\text { in body }\end{array}$ & $\begin{array}{c}\text { Species of } \\
\text { cyanobacteria }\end{array}$ \\
\hline \multirow[t]{2}{*}{$\begin{array}{l}\text { Cyclic } \\
\text { peptides }\end{array}$} & Microcystin & Liver & $\begin{array}{c}\text { Microcystis, } \\
\text { Anabaena, } \\
\text { Planktothrix } \\
\text { (Oscillatoria), } \\
\text { Nostoc, } \\
\text { Hapalosiphon, } \\
\text { Anabaenopsis }\end{array}$ \\
\hline & Nodularin & Liver & Nodularia \\
\hline \multirow{6}{*}{ Alkaloids } & Anatoxin-a & Nerve synapses & $\begin{array}{c}\text { Anabaena, } \\
\text { Planktothrix } \\
\text { (Oscillatoria), } \\
\text { Aphanizomenon }\end{array}$ \\
\hline & Anatoxin- $a(\mathrm{~S})$ & Nerve synapses & Anabaena \\
\hline & Cylindrospermopsin & Liver & $\begin{array}{c}\text { Cylindrospermopsis, } \\
\text { Aphanizomenon, } \\
\text { Umezakia }\end{array}$ \\
\hline & Lyngbiatoxin $-a$ & $\begin{array}{c}\text { Skin, } \\
\text { gastrointestinal } \\
\text { tract }\end{array}$ & Lyngbya \\
\hline & Saxitoxin & Nerve axons & $\begin{array}{c}\text { Anabaena, } \\
\text { Aphanizomenon, } \\
\text { Lyngbya, } \\
\text { Cylindrospermopsis }\end{array}$ \\
\hline & Lipopolysaccharides & $\begin{array}{l}\text { Iriant; affects } \\
\text { all tissues } \\
\text { exposed to its } \\
\text { action }\end{array}$ & All \\
\hline Policets & Apliziatoxins & Skin & $\begin{array}{c}\text { Lyngbya, Schizothrix, } \\
\text { Planktothrix } \\
\text { (Oscillatoria) }\end{array}$ \\
\hline Amino acid & BMAA & Nerve system & All \\
\hline
\end{tabular}


these species are toxins and it is likely that there are still unknown toxins.

People are mostly exposed to cyanobacterial toxins by drinking or bathing in contaminated water. Other sources include algae in the form of tablets in food supplements (Spirulina). Some species form water foam, which is a specific hazard to human health due to the extremely high concentration of toxin. Contact, especially from children, should be avoided.

\section{Spirulina}

Spirulina is cyanobacteria (blue-green algae) that can be eaten by humans and animals. There are two species Arthrospira platensis and Arthrospira maxima. Arthrospira grows around the world in organic cultures. They are used as a dietary supplement such as included in tablets, flakes or powder. It is also used as a food additive in aquaculture, aquarium and poultry industry. Spirulina is a rich source of protein (50-70\%), as well as many vitamins B1 (thiamine), B2 (riboflavin), B3 (nicotinamide), B6 (pyridoxine), B9 (folic acid) and vitamin E.

Spirulina is a form of cyanobacteria, some of which are known to produce toxins, such as microcystins, $\beta$-Methylamino-L-alanine (BMAA), and others. Certain spirulina supplements have been found to be microcystin, albeit below the threshold levels defined by the WHO. Microcystin can cause gastrointestinal disorders and, in the long term, liver cancer. The effects of chronic exposure to even very low levels of microcystins are important because of the potential risk of carcinogenic diseases and neurodegenerative diseases (Holtcamp 2012).

\section{Distribution in water basins}

Cyanobacteria can multiply rapidly in favorable conditions, such as serene, nutrient-rich fresh or sea water in warm climates or at the end of the summer months in the cool parts of the world. Blooms of cyanobacteria can be produced several times in the same water, with the risk of repeated exposure to some human populations. Cyanobacterial toxins have long been known in lakes and marshes in various parts of the world that cause poisoning in animals and humans; one of the earliest reports of their toxic effects was in China 1000 years ago (Chorus and Bartram 1999).

Cyanotoxins are classified according to their organ specificity:

- Neurotoxins - toxins that have a damaging effect on nerve cells cause paralysis and muscle cramps but are thought to be the cause of some neurodegenerative diseases such as Parkinson's and Alzheimer's disease; (World Health Organization (WHO), Geneva).

- Cytotoxins - damage cell structure, cell membrane by impairing its permeability and thus integrity of cells; cause gastrointestinal diseases;
- Endotoxins - toxins that act on intracellular structures such as microtubules or endoplasmic reticulum and disrupt metabolism in the cell; cause gastrointestinal and kidney disease

- Hepatotoxins - damaging the liver; toxins can enter hepatocytes through a specific mechanism of the socalled enterohepatic circulating bile acids (cholera and taurocholic acids). Microcystins inhibit serine / threonine-specific protein phosphatases (PPS), such as PP1 and PP2A, by binding these enzymes. Acute MC toxicity can be explained by what phosphate inhibitor leads to excessive phosphorylation of proteins and changes in cytoskeleton and loss of cellular form, with subsequent breakdown of liver cells causing intrahepatic hemorrhage or hepatic failure.

\section{Cyanotoxins are classified according to their chemical structure (Clark at al. 1999)}

\section{Cyclic peptides}

The term "peptide" means a short-chain polymer made up of amino acids linked together by peptide bonds. The peptides have the same chemical structure as the proteins, the only difference being that the peptide chains are shorter. Cyclic peptides are stable structures, leading to their inability to be degraded in the mammalian organism, and ultimately to their accumulation in the liver. Of all cyanotoxins, cyclic peptides pose the greatest threat to human health. Microcystins and nodulars cause liver intoxication, and in large doses - death. Taking them in small doses with drinking water for an extended period of time can lead to liver cancer, as well as to other organs (Chorus and Bartram 1999).

\section{Microcystins}

Like other cyanotoxins, microcystins are called the first organism that has been found to produce - Microcystis aeruginosa. Later it was found that they are also produced by other cyanobacterial families (Chorus and Bartram 1999). There are about 60 known types of microcystins, some occurring during flowering. Most reports are microcystin-LR, most likely due to the fact that the first availa-

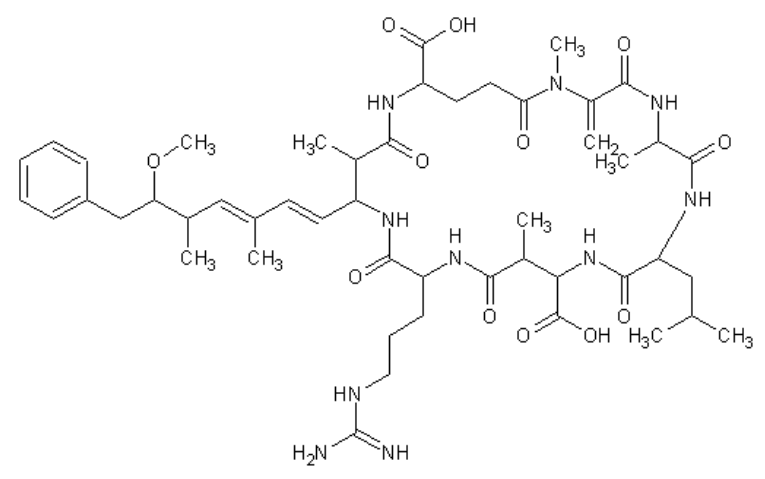

Figure 1. Structure of microcystin-LR. 
ble chemical standard was precisely for microcystin-LR (Chorus and Bartram 1999).

Blossoming micro civils are a problem affecting freshwater ecosystems worldwide (Pelaez et al. 2010). Microcysts are cyclic peptides, which can be extremely dangerous for plants and animals, as well as for humans - they accumulate in fish liver, hepatopancreas, and zooplankton. They are hepatotoxic and can cause serious liver damage in humans (Chorus and Bartram 1999). In this respect, they are close to nodular and together they cause the majority of toxic cyanobacterial blooms in fresh and brackish waters (Chorus and Bartram 1999). In 2010, poisoning of marine otters with microcysts was reported, and the most likely source of this poisoning was seashells. This is the first example of the death of mammals as a result of cyanotoxin uptake (Miller et al. 2010).

\section{Nodularins}

The first identifying type of nodularins was nodularin-R, which is produced by cyanobacteria Nodularia spumigena (Sivonen et al. 1989). This cyanobacteria blooms in the water basins all over the world. Globally, the most common cyanotoxins are cyclic peptide toxins of the nodular family.

Like the microcystin group, nodulars are potent hepatotoxins and can cause serious damage to the liver. They endanger the health of wild and domestic animals as well as humans and in many places seriously impede the provision of safe drinking water (Chorus and Bartram 1999).

\section{Alkaloids}

Alkaloids are a group of natural compounds that in most cases contain basic nitrogen atoms. They are produced by a large number of organisms, including cyanobacteria, and belong to secondary metabolites. Alkaloids affect the function of different systems in animals and humans, and<smiles>C/C=C(\C(=O)O)C(=O)N[C@@H](C(=O)O)[C@@H](C)C(=O)N[C@@H](CCCNC(=N)N)C(=O)N[C@H](/C=C/C(C)=C/[C@H](C)[C@H](Cc1ccccc1)OC)[C@@H](C)C(=O)N[C@@H](CCC(=O)N(C)C(=O)O)C(=O)O</smiles>

Figure 2. Structure of Nodularin- R.

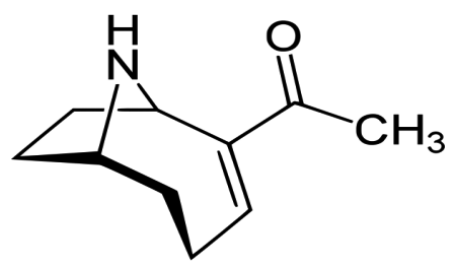

Figure 3. Structure of anatoxin-a. their effects are often psychotropic or toxic. They usually have a bitter taste (Rhoades 1979).

\section{Anatoxin- $\alpha$}

Research on anatoxin-a, also known as the "very rapid lethal factor" - began in 1861, following the death of cows, drinking water from a seaweed lake in Canada (Carmichael and Gorham 1978; Carmichael et al. 1975). This toxin is produced by at least four different cyanobacteria and its presence has been reported in North America, Europe, Asia and New Zealand.

Toxic effects of anatoxin occur very rapidly as it acts directly on neurons. Symptoms of poisoning with it include loss of coordination, tremor, and recent deaths resulting from respiratory paralysis. Stimulation of nicotinic acetylcholine receptors leads to muscle contraction. The anatoxin- $\alpha$ molecule has a form resembling the form of the natural neurotransmitter, acetylcholine, which binds to this receptor. Initiating the contraction, anatoxin prevents neurons from returning to their resting state as it cannot be degraded by the cholinesterase that breaks down acetylcholine. As a result, muscle cells are in constant contraction, coordination between them and the CNS is impaired, and breathing stops.

Anatoxin is called a "very rapid lethal factor" since, after injection into the body of mice, it causes tremor, paralysis, and death within a few minutes. In 1977, it was found to be a secondary bicyclic amine alkaloid and then renamed to anatoxin. In its structure, anatoxin is similar to cocaine. The continued interest in it is due to the fact that its presence in both marine and drinking water poses a serious threat to the life of humans and other living organisms and to the fact that it is a suitable molecule for the study and investigation of acetylcholine receptors in the nervous system (Stewart et al. 2008). Last but not least, due to its lethal properties, anatoxin has the potential for application as a biological weapon (Dixit et al. 2005).

\section{Cylindrospermopsin}

Cylindrospermopsin was first detected after a mysterious disease exploded in Palm Island, Australia. The emergence of this disease is associated with the flowering of Cylindrospermopsin raciborskii in a local drinking water reservoir, and the toxin is also identified.

There are several types of both toxic and non-toxic isolated and synthesized Cylindrospermopsins (Griffiths and Saker 2003). Cylindrospermopsin is toxic to the liver and kidneys. It is thought to inhibit protein synthesis and to modulate covalently the DNA and/or RNA molecules. Toxic flowering of the genera producing cylindrospermopsin are the most common in tropical and subtropical wa-

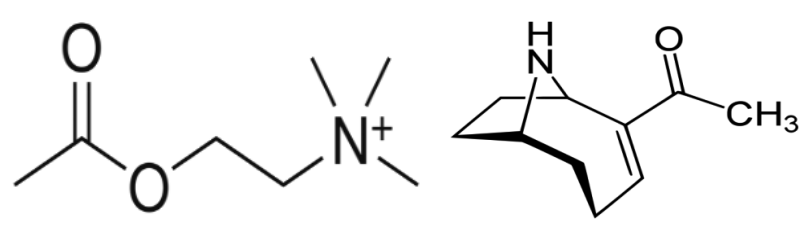

Figure 4. Structural similarity between acetylcholine and anatoxin. 
<smiles>C[C@@H]1[C@H]2CNC3=[N+]2[C@H](C[C@H]([C@H](O)c2cc(=O)[nH]c(=O)[nH]2)N3)C[C@H]1OS(=O)(=O)[O-]</smiles>

Figure 5. Structure of Cylindrospermopsin.

ter bodies as well as in those located in dry areas and have recently been plagued in Australia, Europe, Israel, Japan and the United States (Chorus and Bartram 1999).

\section{Saxotoxin}

Saxitoxin (STX) is one of the strongest known natural neurotoxins. Its name derives from the name of the genus of the clam (Saxidomus giganteus) in which it was first discovered. Saxitoxin is also produced by cyanobacteria of the species Anabaena spp., As well as by some representatives of the species Aphanizomenon spp., Cylindrospermopsis sp., Lyngbya sp. and Planktothrix sp. (Clark et al. 1999). In addition, inflating fish and some marine dinoflagellates also produce saxitoxin. Saxitoxins accumulate in clams and crustaceans, and also in some fish. Swallowing them, usually due to the consumption of seafood contaminated with toxic algal blooms, can lead to paralysis (Chorus and Bartram 1999).

Mechanism of action of saxitoxins:

Saxitoxin is an inhibitory neurotoxin that causes paralysis by actively suppressing the excitation of nerve impulses. High affinity for site 1 binding of voltage-dependent sodium ion channels. STX reversibly inhibits the permeability of sodium ions by binding to a cell surface receptor. Channel blocking in humans prevents depolarization of the membrane and inhibits the subsequent impulse in the peripheral nerves and skeletal muscles, resulting in prolonged relaxation; paralysis. In addition, STX has a tendency to connect to certain low-voltage $\mathrm{Na}+$ channels as well as specific membrane receptors.

In molecular biology, saxitoxins are used to determine the function of the sodium ion channel. Blocking of neuronal sodium channels, which occurs as a result of posing with shellfish and shellfish, causes paralysis in which the muscles are in a relaxed state and deat, in this case, occurs as a result of respiratory failure. For the first time, saxitoxin was isolated and described by an American military who described it as a chemical weapon called "TZ".

\section{Lipopolysaccharides}

Lipopolysaccharides occur in all cyanobacteria. Although they are not as strong as other cyanotoxins, some resear-<smiles>N=C1N[C@H]2[C@H](OC(N)=O)NC(=[NH2+])N3CCC(O)(O)[C@]23N1</smiles>

Figure 6. Structure of Saxitoxins.<smiles>CNC[C@H](N)C(=O)O</smiles>

Figure 7. BMAA structure.

chers claim that these toxins can cause skin irritation, while others place their toxic effects in doubt (Stewart et al. 2006).

\section{Amino Acids}

The non-proteinogenic amino acid BMAA ( $\beta$-Methylamino-L-alanine) is produced by cyanobacteria in marine, freshwater, brackish and terrestrial ecosystems.

The exact mechanism by which BMAA exerts its toxic effect on nerve cells is still under investigation. Studies are also being conducted to determine whether BMAA is a potential risk factor for the development of neurodegenerative diseases, including amyotrophic lateral sclerosis, Parkinson's and Alzheimer's.

\section{Routes of intoxication}

- Oral

- Intranasal / inhaled

- Intravenous

- Intraperitoneal (dialysis treatment)

- Percutaneous

The most important mechanism of intoxication is oral - it involves not only drinking water containing cyanobacteria but also the consumption of toxin-contaminated animal and plant tissues (eg fish consumption). Dietary supplements prepared from cyanobacterial-containing products are also a possible source of contamination. $\mathrm{Hu}-$ man chronic health is more important for chronic exposure to low levels of toxins than acute poisoning.

\section{Mechanism of toxic action of some cya- notoxins and saxitoxins.}

Poisoning seafood has been recognized as a problem for millennia. Many species of crustaceans from the crustaceans to the largest fish are involved. The severe cases of many different types of seafood poisoning can lead to 
deaths. While the pathophysiology of toxins is known in some cases, others, such as ciguatera, remain a little confusing. As a result, treatment of these conditions remains controversial, although supportive care remains the basis for therapy (Clark et al. 1999).

It is of utmost importance that focusing on anatoxin- $\alpha$ is one of the most toxic saxitoxins found in saltwater, shellfish, and crustaceans.

Saxitoxin has a structural similarity to acetylcholine neurotransmitter. Because of this similarity, saxitoxin is a potent neurotoxin. It irreversibly binds to nicotinic acetylcholine receptors and cannot be degraded by acetylcholinesterase nor by pseudocholinesterase. There are a neuromuscular block and loss of coordination, convulsions, stop breathing.

Another interesting feature of the study is Cylindrospermopsins a powerful neuro-, nephron- and hepatotoxin.

The mechanism of toxicity of this toxin is based on the inhibition of GST, protein synthase and Cyt P450 in the cells. This is due to the active groups - a uracil residue and a C7 hydroxyl group in its molecule. As a result, protein synthesis is inhibited and covalently modulates DNA and/or RNA.

The mechanism of microcystins toxicity - a large group of hepatotoxic substances - has been well studied. Inhibits protein-phosphatases (PP) 1 and 2A - this leads to excessive phosphorylation of structural fragments following cytoskeleton degradation and destruction of the liver microstructure. Shrinkage of hepatocytes from adjacent cells is observed. There are organ failure and hemorrhagic shock.

Saxitoxins are found in crustacean's marine agents and cause the most common paralytic shellfish poisoning PSP. Toxicity of these exotoxins is due to the blocking of voltage-dependent Na channels. Paralysis and death may occur due to stopping breathing. (Clark et al. 1999).

Nodular are hepatotoxins and are considered to be potential cationic agents. Found in the genus Nodularia cyanobacteria, populated freshwater. Inhibits eukaryotic protein-phosphatase 1 and $2 \mathrm{~A}$ but to a greater extent $2 \mathrm{~A}$. This is due to the hydrophobic C20 $\beta$-Amino acid which blocks the active enzyme center of PP by reacting with a hydrophobic pocket in the enzyme and prevents its binding to the substrate. It also causes oxidative stress by reducing GST and CAT.

\section{Conclusion}

As a result of the cyanobacterial blooms and toxins emitted by the cyanobacteria in the Bulgarian water basins, one of the water basins in the country has been found to have harmful blooms. The processes of eutrophication and global climate change are able to increase the number, duration, and spread of toxic algal flowering. Therefore, a long-term study of the release of cyanotoxins, as well as the imposition of continuous monitoring of cyanobacteria and an assessment of the toxicity of the risk ponds used as sources of drinking water are necessary. Despite the fact that priority is given to quality control and the protection of drinking water, it should be borne in mind that cyanotoxin uptake may also diminish indirectly (when bathing or practicing water sports) and that it is possible to transfer cyanotoxins on the food chains.

\section{Acknowledgements}

This work has been carried out in the framework of the National Science Program "Environmental Protection and Reduction of Risks of Adverse Events and Natural Disasters", approved by the Resolution of the Council of Ministers № 577/17.08.2018 and supported by the Ministry of Education and Science (MES) of Bulgaria (Agreement № D01-230/06.12.2018).

\section{References}

Bae M-J, Park Y-S (2014) Biological early warning system based on the responses of aquatic organisms to disturbances: A review. Science of The Total Environment 466-467: 635-649. https://doi.org/10.1016/j. scitotenv.2013.07.075

Chorus I, Bartram J, (1999) Toxic Cyanobacteria in Water: A guide to their public health consequences, monitoring and management. WHO, Geneva, 41-111. https://www.who.int/water_sanitation_ health/resourcesquality/toxcyanbegin.pdf

Clark RF, Williams SR, Nordt SP, Manoguerra AS (1999) A review of selected seafood poisonings. Undersea \& Hyperbaric Medicine 26: 175-184.

Dixit A, Dhaked R, Alam S, Singh L (2005) Military potential of biological neurotoxins. Informa Healthcare 24(2): 175-207. https://doi. org/10.1081/TXR-200057850

Edwards N (1999) Anatoxin. University of Sussex at Brighton. http:// www.chm.bris.ac.uk/motm/antx/antxh.htm

Gavrilescu M, Demnerová K, Aamand J, Agathos S, Fava F (2015) Emerging pollutants in the environment: present and future challenges in biomonitoring, ecological risks and bioremediation. New Biotechnology 32: 147-156. https://doi.org/10.1016/j.nbt.2014.01.001

Geissen V, Mol H, Klumpp E, Umlauf G, Nadal M, van der Ploeg M, van de Zee SE, Ritsema CJ (2015) Emerging pollutants in the environment: A challenge for water resource management. International Soil and Water Conservation Research 3: 57-65. https://doi. org/10.1016/j.iswcr.2015.03.002

Griffiths DJ, Saker ML (2003) The Palm Island mystery disease 20 years on: a review of research on the cyanotoxin cylindrospermopsin. Environ. Environmental Toxicology: An International Journal 18(2): 78-93. https://doi.org/10.1002/tox.10103

Hellou J (2010) Behavioural ecotoxicology, an "early warning" signal to assess environmental quality. Environmental Science and Pollution Research 18: 1-11. https://doi.org/10.1007/s11356-010-0367-2

Holtcamp W (2012) The emerging science of BMAA: do cyanobacteria contribute to neurodegenerative disease? Environmental Health Perspective 120(3). a110-a116. https://doi.org/10.1289/ehp.120-a110 
Lindsey R, Scott M (2010) What are phytoplankton NASA Earth Observatory; European Commission FUTURE BRIEF: Identifying emerging risks for environmental policies March 2016 Issue 13.

Miller MA, Kudela RM, Mekebri A, Crane D, Oates SC, Tinker MT, et al. (2010) Evidence for a novel marine harmful algal bloom: cyanotoxin (microcystin) transfer from land to sea otters. PLoS ONE 5(9) e12576. https://doi.org/10.1371/journal.pone.0012576

Pavlova V (2007) Hygiene and Analytical Aspects of Microcystins Occurrence in Surface Water. PhD Thesis, National Center of Public Health Protection, Sofia.

Pavlova V, Babica P, Todorova D, Bratanova Z, Maršálek B (2006) Contamination of Some Reservoirs and Lakes in Republic of Bulgaria by Microcystins. Acta hydrochimica et hydrobiologica 34(5): 437-441. https://doi.org/10.1002/aheh.200600641

Pintado-Herrera MG, González-Mazo E, Lara-Martín PA (2014) Atmospheric pressure gas chromatography- time-of-flight-mass spectrometry (APGC-ToF-MS) for the determination of regulated and emerging contaminants in aqueous samples after stir bar sorptive extraction (SBSE). Analytica Chimica Acta 851: 1-13. https://doi. org/10.1016/j.aca.2014.05.030

Poynton HC, Vulpe CD (2009) Ecotoxicogenomics: Emerging Technologies for Emerging Contaminants. Journal of the American Water Resources Association 45: 83-96. https://doi.org/10.1111/j.17521688.2008.00291.x

Stewart I, Seawright A, Shaw G (2008) Cyanobacterial poisoning in livestock, wild mammals and birds - an overview. In: In: Hudnell HK (Eds) Cyanobacterial Harmful Algal Blooms: State of the Science and Research Needs. Advances in Experimental Medicine and Biology 619: 613-637. https://doi.org/10.1007/978-0-387-75865-7_28

Stewart I, Webb P, Schluter P, Shaw G (2006) Recreational and occupational field exposure to freshwater cyanobacteria - a review of anecdotal and case reports, epidemiological studies and the challenges for epidemiologic assessment. Environmental Health 5(1): 6. https://doi. org/10.1186/1476-069X-5-6 